\title{
Armonía en tiempos de ruido
}

\author{
Harmony in Times of Noise
}

Harmonia em tempos de barulho

\section{Graciela Herrera-Villalobos \\ Universidad Nacional \\ ROR:: https://ror.org/01t466c14}

Centro de Investigación y Docencia en Educación

División de Educación Básica

graciela.herrera.villalobos@una.cr

https://orcid.org/0000-0003-2153-6990

Laura Salazar-Arias

Universidad Nacional

ROR:: https://ror.org/01t466c14

Centro de Investigación y Docencia en Educación

División de Educación Básica

laura.salazar.arias@una.cr

(iD) https://orcid.org/0000-0003-1021-8153

Milagro Obando-Arias Universidad Nacional

ROR:: https://ror.org/01t466c14 Centro de Investigación y Docencia en Educación División de Educación Básica milagro.obando.arias@una.cr (iD) https://orcid.org/0000-0003-2693-2431

Cristofer Vargas-Oviedo Universidad Nacional

ROR:: https://ror.org/01t466c14 Centro de Investigación y Docencia en Educación

División de Educación Básica cristofer.vargas.oviedo@una.cr https://orcid.org/0000-0002-1885-3672

Resumen: A continuación, sistematizamos nuestra experiencia como tutores de Trabajos Finales de Graduación en medio de la pandemia COVID-19, como una oportunidad de transformar y crear nuevos caminos en los procesos investigativos.

Palabras claves: Investigación; transformación; flexibilización; COVID-19.

Abstract: Following, we systemize our experience as tutors of the Final Graduation Projects in the midst of the COVID-19 pandemic, as an opportunity to transform and create new pathways in investigative processes.

Keywords: Research; transformation; flexibilization; COVID-19. 
https://doi.org/10.15359/ree.24-S.8

https://www.revistas.una.ac.cr/index.php/educare

educare@una.ac.cr

\begin{abstract}
Resumo: A seguir, sistematizamos nossa experiência como tutores dos Trabalhos Finais de Graduação no meio da pandemia COVID-19, como uma oportunidade de transformar e criar novos caminhos nos processos investigativos.
\end{abstract}

Palavras-chaves: Investigação; transformação; flexibilização; COVID-19.

Recibido: 13/07/2020 Aceptado: 07/08/2020

\title{
Introducción
}

"La pandemia y la cuarentena revelan que hay alternativas posibles, que las sociedades se adaptan a nuevas formas de vida cuando es necesario y se trata del bien común" (de Sousa SANTOS, 2020, p.79). El COVID-19, ha traído cambios en nuestra forma de relacionarnos, el cual no representa solamente un problema de salud que ha trascendido fronteras, sino que, para algunos sectores, esta pandemia nos lleva a plantearnos la posibilidad de un cambio de paradigma en lo que hemos entendido y construido como sociedad. Por lo tanto, los procesos de formación académica deben responder a esta transformación según la evolución de los acontecimientos.

\section{Desarrollo}

Desde nuestra figura como tutores y tutoras, ante esta situación de pandemia, pretendemos compartir el proceso de transformación experimentado en el contexto de los trabajos de investigación, dentro de la carrera de Pedagogía con énfasis en I y II Ciclo de Educación General Básica, a nivel de Licenciatura.

Sin duda, esta situación ha obligado a que la educación explore e innove en diferentes escenarios, por lo que estos procesos investigativos deben moverse en la misma corriente del contexto mundial. Por lo tanto, ante la condición actual como profesoras tutoras y profesores tutores, apostamos por procesos reflexivos-dialógicos con el colectivo de estudiantes, para construir soluciones pertinentes para cada uno de los contextos en los que desarrollan cada trabajo, lo cual es un claro ejemplo de la necesidad de flexibilidad y transformación de la investigación.

Si todas las instancias sociales están sufriendo modificaciones desde la funcionalidad, para dar respuesta acorde a los tiempos vividos, la investigación debe acompañar este proceso de transformación. Mejía (2011) expresa que los procesos educativos deben tener como fin la emancipación y transformación con implicaciones individuales hacia las personas que la integramos, al hacer esto, promovemos la construcción de nuevos grupos sociales, en los cuales debemos promover espacios de democracia para llevar a la realidad ideas de igualdad y solidaridad.

Al tratarse de investigación en el aula, en un sentido amplio del concepto, el aula hoy más que nunca no se puede quedar encerrada en la infraestructura de un edificio escolar. 
Las necesidades de aula en este contexto están en donde se encuentren los estudiantes de cada nivel. Por tanto, "un modelo educativo debe garantizar formar profesionales altamente capacitados en habilidades de todo tipo, siendo una de ellas la sensibilidad con los problemas sociales, tanto nacionales como internacionales" (Casasola, 2020, "Entonces, ¿cuál es el reto de la educación", párr. 11).

\section{Conclusión}

Logramos construir armonía entre los procesos de investigación, la cual se abocó en buscar nuevas alternativas en conjunto, dando como resultado una profundización en el impacto de cada trabajo en su contexto, donde la virtualidad y el apoyo a la distancia de diferentes actores inmersos en el proceso investigativo, acompañan y habilitan espacios fundamentales para que las personas estudiantes puedan continuar con su trabajo de campo en tiempo de crisis. En este momento, vemos la articulación entre universidad-comunidad, no solo la universidad contribuyendo con la comunidad, sino una visibilización de una relación recíproca.

Por otro lado, queremos hacer eco, de la importancia del impacto en los diferentes escenarios que tienen los trabajos finales de graduación y cómo estos están contribuyendo en la actualidad en sus realidades y en la atención de las diferentes poblaciones en medio de la emergencia nacional, resaltando el compromiso que cada estudiante ha desarrollado con sus poblaciones.

Por último, queremos resaltar la importancia de la figura docente-investigador en tiempos de pandemia y cómo puede deconstruir, reconstruir o transformar sus procesos investigativos desde este escenario, apuntando una vez más, a que la investigación no es un proceso lineal, sino flexible que puede llevarnos a diferentes rumbos.

Nota general: Corrección de estilo y traducciones a cargo de las personas autoras.

\section{Referencias}

Casasola Rivera, W. (31 de marzo, 2020) Repensar el modelo educativo ante el COVID-19. Hoy en el TEC. https://www.tec.ac.cr/hoyeneltec/2020/03/31/repensar-modelo-educativocovid-19

De Sousa Santos, B. (2020). La cruel pedagogía del virus. CLACSO. http://209.177.156.169/libreria $\mathrm{cm} /$ archivos/La-cruel-pedagogia-del-virus.pdf

Mejía, M. R. (2011). Educaciones y pedagogías críticas desde el sur (Cartografías de la educación popular). Ministerio de Educación, Viceministerio de Educación Alternativa y Especial. http://otrasvoceseneducacion.org/archivos/208632 